\title{
O PROBLEMA DAS RELAÇÕES INTERESTATAIS NO PENSAMENTO POLÍTICO DE ROUSSEAU
}

\author{
Lucas Mello Carvalho Ribeiro ${ }^{1}$
}

\begin{abstract}
Resumo:
O objetivo do presente artigo é explicar o que leva J.-J. Rousseau a afirmar que o conflito é inerente às relações entre Estados. Trata-se, pois, de elucidar o que fundamenta o diagnóstico disposto em seus Principes du droit de la guerre, segundo o qual "o estado de guerra é natural entre as potências". Para tanto, avançamos uma hipótese que pode ser desmembrada em dois eixos interligados. Se o genebrino sustenta que a condição originária das soberanias é de hostilidade mútua - ainda que não deflagrada -, isso se deve (i) a um marcado questionamento da efetividade, se não da possibilidade mesma, de uma regulação jurídica do plano interestatal e (ii) à natureza peculiar do ente político. O primeiro momento desta hipótese irá nos conduzir ao diálogo crítico que Rousseau estabelece com a tradição jusnaturalista, uma vez que o direito natural, pelo menos em sua acepção canônica, impõe-se como princípio de obrigação tanto para os indivíduos quanto para os seres coletivos. Desde essa perspectiva, portanto, as relações interestatais contariam, ab ovo, com um dispositivo normativo. Disso se segue que a guerra seria, invariavelmente, o produto de um desvio, de uma ruptura daquela ordenação preestabelecida; jamais o estado originário do sistema internacional, como pretende Rousseau. Contudo, a recusa de uma normatividade natural não explica, por si, a belicosidade da dinâmica interestatal. É sabido que, sob a ótica rousseauniana, os indivíduos no puro estado de natureza - isto é, aquém do discernimento de quaisquer normas de justiça arrazoada - desconhecem a guerra. Daí o segundo momento de nossa hipótese: é preciso explicitar a profunda diferença entre a natureza humana e aquela dos corpos políticos, de modo a esclarecer por que, deixados a si, os indivíduos dispõem de uma existência pacífica, enquanto as potências tendem ao conflito.
\end{abstract}

Palavras-Chave: Rousseau. Direito natural. Relações interestatais. Corpo político. Estado de guerra.

\section{THE PROBLEM OF INTERNATIONAL RELATIONS IN ROUSSEAU'S POLITICAL THINKING}

\begin{abstract}
:
The goal of the present paper is to explain what compels J.-J. Rousseau to claim that conflict is inherent to the relations between states, elucidating the grounds of the diagnosis brought forth in his Principes du droit de la guerre, according to which "the state of war is natural between powers". In order to do so, one proposes a hypothesis that can be divided in two complementary axes. If the Genevan sustains that the original condition of sovereignties is one of mutual hostility, it is due (i) to a profound questioning of the effectuality, if not of the very possibility, of a legal regulation of the international arena and (ii) to the peculiar nature of the political entity. The first branch of this hypothesis leads us to the critical dialogue that Rousseau establishes with the jusnaturalistic tradition, once natural law, at least in its canonical sense, imposes itself as an obligation principle for both individuals and collective beings. Thus, from this perspective the international relations dispose, $a b$ ovo, of a normative mechanism. In consequence, war would invariably be the product of a deviation, of the rupture of a previous order; and never the original state of the international system, as intended by Rousseau. However, the refusal of a natural normativity does not account, per se, for the belligerence of the dynamic between states. It is well known that, from a Rousseauian point of view, individuals in the pure state of nature - that is, disregarding any rational principles of justice - ignore warfare. Hence the second branch of our hypothesis: one must unravel the significant difference between human nature and the nature of the body politic, as to clarify why, left by themselves, individuals enjoy a pacific existence while sovereign powers are prone to conflict.
\end{abstract}

Keywords: Rousseau. Natural law. International relations. Body politic. State of war.

1 Doutor em Filosofia pela UFMG, com estágio doutoral (PDSE-CAPES) na École des Hautes Études en Sciences Sociales (Paris). Membro da Associação Brasileira de Estudos do Século XVIII e da International Society for Eighteenth-Century Studies. E-mail: lucasmcr@yahoo.com.br. 
“O estado de guerra é natural entre as potências” (ROUSSEAU, 2008, p. 80). Esta sentença, extraída dos Princípios do direito de guerra, é tão fillosoficamente densa quanto lacônica é sua formulação. Por meio dela, Rousseau afirma que as relações interestatais são marcadas pelo conflito. Mais: afirma que certa conflitualidade é constitutiva das mesmas. Com efeito, não se trata de simples observação fática. Não é dito ali que as potências europeias do dezoito ou de um passado acessível por documentos sempre manifestaram entre si algum grau de litigiosidade. Há um peso ontológico nas palavras do genebrino que os eventos históricos não fariam senão referendar: no plano externo, o estado de guerra é originário.

O propósito maior do presente artigo é justamente explicitar o encadeamento teórico-conceitual que subjaz à passagem recém-citada. Para esse fim, aventamos uma hipótese que se divide em dois grandes momentos argumentativos. No nosso entendimento, a adequada compreensão do filosofema de Rousseau requer, preliminarmente, a recuperação de seu questionamento à ideia de direito natural e, em seguida, a explicitação da peculiaridade da natureza do corpo político.

\section{Rousseau e o jusnaturalismo moderno}

Tratemos, primeiramente, do diálogo rousseauniano com a tradição jusnaturalista moderna. Sem dúvida, um tema clássico, mas de modo algum esgotado como alguns pretenderam. Como diz Gabriella Silvestrini (2010, p. 23), a relação de Rousseau com a escola do direito natural dificilmente deixará de ser um "problema em aberto". Isso posto, é preciso, antes de mais nada, entender por que a abordagem desse problema se impõe ao objeto de nossa investigação.

Ao menos em sua acepção canônica, o direito natural, como notou Bruno Bernardi (2014, p. 554), opera como princípio de obrigação não só para indivíduos e cidadãos, mas também para os seres coletivos. Ele pré-existe à vida civil, sobrevive a ela pois mantém-se como métron das leis positivas - e, finalmente, se estende ao âmbito externo na figura do jus gentium. Assim, as relações entre Estados, longe de se mostrarem originariamente anárquicas e contenciosas, estariam desde sempre reguladas por um aparato normativo universal. Portanto, as condições para uma convivência harmônica e pacífica estariam postas $a b$ ovo, de modo que a guerra só poderia ser uma ruptura histórica de uma

\begin{tabular}{|l|l|l|l|l|}
\hline Govista Dialectus & Ano 8 & n. 15 & Agosto - Dezembro 2019 & p. $143-155$ \\
\hline
\end{tabular}


ordenação estrutural, advinda da não observância dos ditames do direito das gentes. Jamais um dado inicial, constitutivo.

Vê-se, de plano, que para afirmar um estado de guerra originário e natural às potências Rousseau não poderá endossar a vigência de um direito das gentes e, por regressão, terá de se afastar em alguma medida do ideário jusnaturalista. Foi esse o nosso ponto de entrada para o exame dessa vexata quaestio que é a interlocução estabelecida pelo genebrino com o jusnaturalismo moderno. Um ponto de entrada que, obviamente, sugere um posicionamento diante da literatura secundária que se ocupou do tema. Mais especificamente, sugere um alinhamento com aqueles que, desde a exegese pioneira de Charles Edwin Vaughan (1915, p. 28 e seguintes), veem em Rousseau um crítico do jusnaturalismo.

Disposto este esclarecimento, passemos a uma breve recapitulação do debate que, em diferentes momentos de sua obra, Rousseau mantém com o jusnaturalismo, doutrina decerto influente, se não amplamente hegemônica, no ambiente intelectual em que ele escreve.

Comecemos pelo Discurso sobre a origem e os fundamentos da desigualdade entre os homens. Talvez seja na primeira parte deste escrito que o genebrino desfira seu ataque mais contundente contra a tradição jusnaturalista, uma vez que, ali, ele tem como alvo a própria pedra angular daquele edifício, a saber, o preceito, tão antigo quanto a filosofia política, da sociabilidade natural. Como se sabe, há uma implicação mútua entre direito e sociabilidade naturais: a lei natural - regra de justiça imutável, anterior e superior às convenções humanas, derivada da natureza racional dos homens (cf. DERATHÉ, 2009, p. 230) - existe justamente para que a destinação social da humanidade se realize a contento (ver, dentre outros, JAUCOURT, 2015, p. 217-219 e LEPAN, 2007, p. 248). As leis naturais responderiam à necessidade de conservação de um convívio social minimamente harmonioso, do qual dependeria, desde sempre, a sobrevivência do gênero humano. Assim, toda teoria jusnaturalista pressupõe ou demonstra o caráter original e necessário da vida partilhada.

Os argumentos que sustentam tal ideia podem ser circunscritos, grosso modo, em dois grandes eixos. De início, a sociabilidade seria um aspecto inelutável da existência humana em virtude de uma necessidade física. $O$ indivíduo, deixado a si, seria constitucionalmente incapaz de prover à própria subsistência, estando fadado a um rápido

\begin{tabular}{|l|l|l|l|l|}
\hline Govista Dialectus & Ano 8 & n. 15 & Agosto-Dezembro 2019 & p. $143-155$ \\
\hline
\end{tabular}


perecimento (cf., por exemplo, PUFENDORF, 1734, p. 222). Para além dessa dimensão estritamente biológica da sociabilidade natural, muitos pensadores, na esteira de Aristóteles (1920, 1252a2), identificaram uma justificativa moral, por assim dizer, para reivindicar a inclinação social da espécie humana. Segundo eles, nossas faculdades distintivas se notabilizam por seu caráter inequivocamente dialógico. E não haveria sentido em dispormos de uma faculdade sem dispormos igualmente das condições para efetivá-la. De maneira que, se somos seres de linguagem e de razão, por exemplo, somos forçosamente, também, seres sociáveis. Encontramos no artigo enciclopédico - "Société" -, provavelmente da lavra de Boucher d'Argis, uma boa síntese da argumentação habitualmente mobilizada em favor da sociabilidade natural:

\footnotetext{
Os homens são feitos para viver em sociedade. Se a intenção de Deus tivesse sido a de que cada homem vivesse sozinho e separado dos outros, ele teria dado a cada um deles qualidades próprias e suficientes para esse gênero de vida solitária. Se não seguiu essa rota, aparentemente, foi porque quis que os laços de sangue e de nascimento começassem a formar entre os homens essa união mais estendida que queria estabelecer entre eles. A maior parte das faculdades do homem, suas inclinações naturais, sua fraqueza, suas necessidades [besoins] são provas certas dessa intenção do Criador. Tal é, com efeito, a natureza e a constituição do homem, que, fora da sociedade, ele não poderia nem conservar sua vida, nem desenvolver e aperfeiçoar suas faculdades e seus talentos [...] (2015, p. 336).
}

Pois bem, a primeira parte do Discurso sobre a desigualdade contempla uma contundente refutação do raciocínio recém-exposto. O indivíduo fraco, inapto a granjear seu próprio sustento, é um indivíduo já desnaturado, fruto de um longo processo civilizatório que altera sua conformação corpórea. Aqueles que insistem na fraqueza do homem natural - em tese, remediável apenas pelo recurso à socialização - projetam na humanidade originária um reflexo especular, menosprezando a advertência metodológica do genebrino: "Evitemos confundir o homem selvagem com os homens que temos diante dos olhos" (ROUSSEAU, 1964a, p. 139). O mesmo se passa relativamente à configuração anímica do ser humano: nem razão, nem linguagem, nem liberdade ou perfectibilidade - estas últimas as características propriamente distintivas do gênero humano segundo Rousseau - são ativas no puro estado de natureza. Neste estado primitivo, dado o perfeito equilíbrio entre suas poucas necessidades e aquilo que lhe é oferecido pelo ambiente em que vive, o indivíduo não tem uso para a reflexão ou para a linguagem (ROUSSEAU, 1964a, p. 159-160). Suas ações são orientadas exclusivamente por seu aparato instintual - amor de si e piedade. Suas demais faculdades encontram-se, todas, adormecidas. Ele as possui, mas apenas em potência (ROUSSEAU,

\begin{tabular}{|l|l|l|l|l|}
\hline Gevista Dialectus & Ano 8 & n. 15 & Agosto-Dezembro 2019 & p. $143-155$ \\
\hline
\end{tabular}


1964a, p. 162). Dessa maneira, podemos dizer, com o Rousseau do Emílio, que o ser humano foi feito para tornar-se sociável (1969, p. 600), mas não que ele seja originária e naturalmente sociável.

De imediato, o direito natural se vê sem assento. Como conceber a vigência de uma instância normativa aferidora de direitos e deveres em um cenário no qual os indivíduos, autossuficientes, vivem dispersos uns dos outros?, no qual sequer há trocas sociais a serem reguladas?

Diante disso, talvez muitos fossem levados a crer que a impugnação rousseauniana do jusnaturalismo estivesse concluída. Rousseau, não obstante, aprofunda seus questionamentos, claro indício da importância que a contestação do conceito clássico de direito natural adquire em seu sistema de pensamento. Ele o faz, sobretudo, no célebre capítulo 2 do Manuscrito de Genebra - a primeira versão do Contrato social. Um capítulo que, sabemos, tem um adversário claro: o artigo "Droit naturel", que Diderot escreve para o quinto volume da Encyclopédie.

Ao contrário do que se verifica na primeira parte do segundo Discurso, no Manuscrito de Genebra Rousseau adota um expediente francamente concessivo, aquiescendo provisoriamente aos pressupostos jusnaturalistas, para, de dentro, colocar em xeque as conclusões deles extraídas ${ }^{2}$.

Inicialmente, ele põe em suspenso todas as sobredescritas ressalvas quanto à sociabilidade natural, supondo os indivíduos, desde sempre, agrupados em sociedade; uma conjuntura apta, portanto, a receber a ordenação das leis naturais (cf. ROUSSEAU, 1964b, p. 281-282).

$\mathrm{Na}$ sequência, ele concede à postulação de que, nesse socius originário, os indivíduos já disporiam de luzes suficientes para discernir os ditames daquelas leis: não nos esqueçamos que a lei de natureza é uma lei de razão, e que o acesso ao seu conteúdo se dá precisamente por um "ato do entendimento" (DIDEROT, 2015, p. 106; cf. também RADICA, 2008, p. 42-45). A esse ponto, aparece seu primeiro contra-argumento: no mesmo instante em que a razão emerge, despontam também inclinações egoístas de toda sorte, que contrabalanceiam a tendência racional que nos dirige até a vontade geral da espécie

2 No fragmento "Idée de la méthode dans la composition d'un livre", Rousseau (1964, p. 1242-1243) explicita os benefícios da "argumentação concessiva", aplicada em diversos momentos de sua teorização.

\begin{tabular}{|l|c|c|c|c|}
\hline Revista Dialectus & Ano 8 & n. 15 & Agosto-Dezembro 2019 & p. $143-155$ \\
\hline
\end{tabular}


(ROUSSEAU, 1964b, p. 283) - esse verdadeiro "tribunal do gênero humano", segundo Diderot (2015, p. 105). Aquele ato de entendimento teria de "silenciar as paixões", como admite o enciclopedista, tarefa cuja viabilidade é vista com grande ceticismo por Rousseau. Mesmo assim, o genebrino se mostra disposto a mais essa concessão a seu "frère enemmi" (FABRE, 1961, p. 156).

Somos seres sociáveis e nossa porção racional logra se impor sobre o amorpróprio. Ainda nesse contexto as máximas do direito natural seriam inócuas, pois não seriam obedecidas. Por quê? Entra em cena, afinal, o problema da sanção, que deteve todos os grandes expoentes do jusnaturalismo moderno. Para Rousseau (como para Hobbes, diga-se), na ausência da espada pública os apelos da razão e, eventualmente, o temor de um castigo divino não bastariam para garantir o cumprimento generalizado das leis naturais (cf. ROUSSEAU, 1964b, p. 285 e HOBBES, 1651, p. 131). Na ausência dessa garantia, a própria razão desaconselharia a obediência à lei natural, que só seria benéfica para o indivíduo se todos os demais também a respeitassem. A falta de sanção do direito natural acaba por acarretar um divórcio entre justiça e utilidade. E, sempre amparado em um consciente realismo antropológico, Rousseau sustenta que ninguém será justo em detrimento de si. Cada um seguirá seu estrito interesse enquanto não vislumbrar a utilidade em ser justo:

[...] as leis sociais ${ }^{3}$ são um jugo que cada um quer bem impor aos outros, mas não assumir para si. "Sinto que trago pavor e perturbação à espécie humana", diz o homem independente [referência ao 'raisonneur violent', de Diderot] que o sábio sufoca, "mas é preciso ou que eu seja infeliz ou que faça a infelicidade dos outros, e ninguém me é mais caro do que sou a mim mesmo". "Em vão", ele poderia acrescentar, "tentaria conciliar meu interesse com aquele de outrem; tudo o que me dizeis sobre as vantagens da lei social poderia ser bom se, enquanto eu a observasse escrupulosamente em relação aos outros, estivesse certo de que todos a observariam em relação a mim. Mas que certeza podeis me dar a esse respeito? E minha situação poderia ser pior do que me ver exposto a todos os males que os mais fortes gostariam de me fazer sem ousar buscar compensação sobre os mais fracos? Dai-me garantias contra toda empresa injusta ou não esperai que delas me abstenha. Podereis dizer-me que, renunciando aos deveres que a lei natural impõe a mim, privo-me ao mesmo tempo de seus direitos, e que minhas violências autorizarão todas aquelas que querer-se-á cometer contra mim. A isso consinto tanto mais de bom grado quanto não vejo como minha moderação poderia delas me proteger. Mais ainda, empenhar-me-ei em ter os fortes ao meu lado, partilhando com eles os despojos dos fracos. Para meu proveito e para minha segurança, isso valerá mais do que a justiça”. A prova de que é assim que teria raciocinado o homem esclarecido e independente está no fato de que é assim que teria raciocinado toda sociedade soberana que não presta contas de sua conduta senão a si mesma.

3 Nesse contexto, a expressão "loix sociales" deve ser compreendida, a nosso ver, em oposição às "loix civiles". Quer dizer, são leis distintas das leis de convenção que acompanham a instituição de um Estado. Dito de outro modo, as "loix sociales" são, ali, um outro modo de designar as "loix naturelles", o que é atestado pela alternância indiscriminada das duas locuções ao longo do parágrafo.

\begin{tabular}{|c|c|c|c|c|}
\hline Revista Q Dialectus & Ano 8 & n. 15 & Agosto - Dezembro 2019 & p. $143-155$ \\
\hline
\end{tabular}


[...] É à vontade geral que o indivíduo deve se dirigir para saber até que ponto ele deve ser homem, cidadão, súdito, pai, filho e quando convém-lhe viver ou morrer [temos aqui, novamente, uma interpolação diderotiana]. "Vejo bem aí, confesso, a regra que posso consultar, mas ainda não vejo", dirá nosso homem independente, "a razão de assujeitar-me a essa regra. Não se trata de me ensinar o que é a justiça; trata-se de me mostrar qual interesse tenho em ser justo" (ROUSSEAU, 1964b, p. 284-286). ${ }^{4}$

Enfim, após tantas concessões, a conclusão do Manuscrito de Genebra é absolutamente afim ao que pudemos depreender do segundo Discurso: o direito natural, qual disposto por Diderot em seu artigo (uma espécie de súmula da tradição), "é uma verdadeira quimera”, factível apenas nos "sistemas dos Philosophes" (ROUSSEAU, 1964b, p. 284).

A mise en question do direito natural não poderia deixar de refletir no âmbito do direito das gentes, extensão do direito natural para o plano externo, para o domínio dos seres coletivos: "Se no estado de natureza não há nada que vincule os homens, então nada, tampouco, vincula as nações entre si”, dirá Marc Bélissa (1998, p. 34). Dessa forma, vemos que para Rousseau, contrariamente a tantos de seus predecessores e contemporâneos, não há nenhum tipo de normatividade espontânea a ordenar a conduta dos Estados. Não haveria razões, portanto, para estabelecer a paz como estado natural/normal dos corpos políticos, como o faz Damilaville (2008, p. 768) no verbete enciclopédico intitulado "Paix":

Hobbes propôs que os homens estavam em um estado de guerra incessante; o sentimento desse filósofo atrabiliário não parece mais bem fundado do que se ele tivesse dito que o estado de dor e doença é natural ao homem. Assim como os corpos físicos, os corpos políticos estão sujeitos a revoluções cruéis e perigosas. Embora essas enfermidades sejam consequências necessárias da fraqueza humana, elas não podem ser consideradas um estado natural. A guerra é fruto da depravação dos homens [e dos Estados]; é uma doença convulsiva e violenta do corpo político. Ele goza de saúde - quer dizer, ele está em seu estado natural - apenas quando está em paz $[\ldots]$.

\section{A natureza do corpo político e as relações entre Estados}

Aqui, precisamos ser bastante cautelosos. Devemos resistir a qualquer equacionamento entre a negação da paz como estágio originário das relações interestatais e a

4 Para um comentário, ver SPECTOR, 2012, p. 151.

\begin{tabular}{|l|c|c|c|c|}
\hline Q Povista Dialectus & Ano 8 & n. 15 & Agosto-Dezembro 2019 & p. $143-155$ \\
\hline
\end{tabular}


afirmação de uma belicosidade intrínseca às mesmas. Se a ausência de uma normatividade natural ordenadora da dinâmica externa é, sim, condição necessária e preliminar para o diagnóstico rousseauniano (GOYARD-FABRE, 1995, p. 65), ela não é, todavia, sua condição suficiente. Lembremos que o mesmo autor que propõe que "os Estados, pelo simples fato de existirem simultaneamente, estão de facto se não em guerra, ao menos em estado de guerra" (BACHOFEN, 2008, p. 146), é veemente ao defender que, no primeiro estado de natureza marcado precisamente por uma completa carência de dispositivos de justiça arrazoada - os indivíduos dispõem de uma existência pacífica. (Aliás, no mesmíssimo escrito em que avança com mais clareza a tese de que o estado natural entre as potências é o estado de guerra, Rousseau (2008, p. 70) faz questão de se distanciar do "horrível sistema de Hobbes", rechaçado exatamente por reputar a guerra como decorrência da natureza humana e, ato contínuo, como condição primeva das relações interindividuais.)

Somos, então, confrontados com a seguinte questão: por que, deixados a si, os indivíduos gozam originariamente de uma existência pacífica, ao passo que as potências tendem ao embate? Ou, nas palavras de Grace Roosevelt (1990, p. 37): "por que os corpos políticos não conseguem coexistir pacificamente, como o fazem os homens no estado de natureza?". Ora, se "a guerra não é natural aos seres humanos, mas é natural aos Estados" (ROOSEVELT, 1990, p. 37), "se o homem é naturalmente pacífico [e] o Estado naturalmente belicoso" (LASSUDRIE-DUCHÈNE, 1906, p. 171), é porque a natureza de ambos é distinta. Impõe-se-nos, portanto, a explicitação dessa diferença.

Para aclará-la, Rousseau aposta em um efeito de contraste, cotejando o Estado ao indivíduo em sua dimensão estritamente física. Como resultado, este último aparece como um ser de grandeza fixa, circunscrita em parâmetros estreitos pelas mãos da natureza:

\footnotetext{
o homem tem um limite de força e de grandeza [...] o qual não conseguiria ultrapassar. Sob qualquer ângulo que se observe, ele encontra todas suas faculdades limitadas. Sua vida é curta, seus anos são contados. Seu estômago não se expande com suas riquezas; suas paixões podem até aumentar, seus prazeres têm sua medida; seu coração é limitado como todo o resto, sua capacidade de fruição é sempre a mesma. Ainda que se eleve em pensamento, permanece pequeno. (ROUSSEAU, 2008, p. 76)
}

Desse caráter absoluto do corpo humano decorre uma implicação da maior importância: tendo um limite de grandeza fixado pela natureza e sendo suficientemente robusto para suprir o próprio sustento, "o ser humano", no puro estado de natureza, "não tem nenhuma relação necessária com seus semelhantes, pode subsistir, em todo o seu vigor, sem o

\begin{tabular}{|l|l|l|l|l|}
\hline Govista Dialectus & Ano 8 & n. 15 & Agosto-Dezembro 2019 & p. $143-155$ \\
\hline
\end{tabular}


concurso destes" (ROUSSEAU, 2008, p. 76). Condição que lhe faculta uma existência pacífica: "constitutivamente capaz de ser autônomo, o homem natural também é, portanto, capaz de viver em paz" (ROOSEVELT, 1990, p. 37).

Nos antípodas desse retrato, apresenta-se a caracterização rousseauniana do corpo político: "O Estado, ao contrário, [...] não tem nenhuma medida determinada, a grandeza que lhe é própria é indefinida. Ele pode sempre aumentá-la [ou diminuí-la...]" (ROUSSEAU, 2008, p. 76). O corpo político é constitutivamente ilimitado, não tem qualquer parâmetro predeterminado. Sua natureza é absolutamente proteiforme. Conforme Roosevelt (1990, p. 37): "Em contraste com o homem natural, autossuficiente e naturalmente limitado, o estado é um ser artificial sem nenhum limite de grandeza fixado ou necessário”. Traço que não é sem repercussões nos planos geográfico e demográfico: “O Estado é um corpo cujas características são diametralmente opostas àquelas do homem [natural]. Ele é indeterminado" e, "enquanto corpo indeterminado, não possui dimensões territoriais preconcebidas, nem número dado de habitantes. Ele pode se estender sem limites e, igualmente, aumentar a densidade humana em seu interior de maneira indefinida” (RAMEL \& JOUBERT, 2000, p. 105).

Dessa indeterminação constitucional decorre seu pendor relacional. O retraimento solitário não é uma opção para o corpo político, sua existência será sempre relativa ao que lhe é exterior. Ele só poderá fazer uma imagem acurada de si depois de um cotejo com seus vizinhos, o conhecimento de si passará necessariamente pela alteridade. Não apenas sua força é determinada exclusivamente por uma comparação constante com as demais, mas qualquer mudança em sua configuração só será alcançada em detrimento ou proveito de outras potências. $\mathrm{O}$ robustecimento de um Estado significa necessariamente o enfraquecimento de outro:

[O Estado] não pode exercer suas forças senão às expensas de seus vizinhos [...]. Assim, a grandeza do corpo político, sendo puramente relativa, ele é forçado a se comparar sem cessar para se conhecer; ele depende de tudo aquilo que o cerca e deve tomar interesse em tudo que aí se passa, pois, mesmo que queira se manter dentro de si sem nada ganhar nem perder, torna-se pequeno ou grande, fraco ou forte, segundo seu vizinho se estenda ou se retraia e se reforce ou se enfraqueça.

Há, portanto, uma propensão para o encontro inscrita na natureza mesma das potências soberanas. Some-se a isso o fato há pouco deslindado de que, na ausência de um direito comum, não há mediação institucional para esses encontros, e conclui-se que os inevitáveis atritos entre Estados serão, fatalmente, colisões violentas. A contenciosidade está,

\begin{tabular}{|l|l|l|l|l|}
\hline Govista Dialectus & Ano 8 & n. 15 & Agosto-Dezembro 2019 & p. $143-155$ \\
\hline
\end{tabular}


pois, "inscrita na natureza da coisa política [...] em ato e potência. Em Rousseau, a guerra é a consequência irresistível e imediata da criação dos Estados pela arte humana" (RAMEL \& JOUBERT, 2000, p. 107). O estado de guerra é mesmo a modalidade originária e normal de suas relações, "é a condição geral das sociedades [políticas] entre si" (BERNARDI, 2006, p. 237). Uma condição que não é secundária ou acidental, posto ser inerente à forma-Estado. $\mathrm{O}$ conflito é o horizonte persistente do panorama interestatal, ele está gravado na própria natureza do corpo político. A tese forte dos Princípios encontra-se, enfim, justificada.

Desde a perspectiva rousseauniana, a paz não é uma arché, uma condição principial, senão um télos, um fim a ser perseguido (cf. FRINGS, 1975, p. 85). A paz sempre envolverá algum esforço de pacificação, que não é simplesmente restauração de uma conjuntura inaugural perdida, mas, antes, a edificação de algo jamais plenamente alcançado. Como coloca Simone Goyard-Fabre (1994), a paz será invariavelmente uma construção.

É ainda Goyard-Fabre (1994, p. 10) que alude a essa construção como um "trabalho de Sísifo", imagem que, a nosso ver, representa muito bem o espírito da teorização rousseauniana. Não só o estabelecimento da paz exige um trabalho, mas trata-se de um esforço que sempre opera contra uma resistência primária. No caso, a natureza mesma dos corpos políticos, sempre propensos, vimos, à comparação e aos enfrentamentos.

A figura de Sísifo, que se aplica tão bem à reflexão rousseauniana sobre a política externa, também pode ser de grande pertinência, diga-se, para retratar seu pensamento sobre o campo doméstico, sobre a relação entre o Estado e seus cidadãos.

Se no plano externo todo esforço de pacificação esbarra em uma tendência natural ao conflito que deve ser ultrapassada, no plano interno a construção e preservação de uma República bem ordenada, quer dizer, a construção e preservação de um Estado em que a lei enquanto expressão da vontade geral seja respeitada, também se choca contra um pendor inexorável. Nomeadamente, o inevitável processo de afastamento e autonomização dos representantes em relação aos representados (cf. ROUSSEAU, 1964c, p. 428-431 e DERRIDA, 2006, p. 177), a inclinação, comum a qualquer corpo de governo, em usurpar a soberania popular da qual deveria ser apenas o delegado.

\begin{tabular}{|l|l|l|l|l|}
\hline Q Povista Dialectus & Ano 8 & n. 15 & Agosto - Dezembro 2019 & p. $143-155$ \\
\hline
\end{tabular}


Portanto, em ambos os registros, interno e externo, trabalha-se contra uma resistência. Em ambos, antepõe-se entre o ator político (o povo e os Estados) e o fim almejado (a liberdade e a paz) um obstáculo natural.

Há um aspecto, entretanto, em que a metáfora deixa de ilustrar adequadamente o domínio do político. Na mitologia grega, o trabalho de Sísifo é um castigo, uma danação eterna. E, como tal, tornou-se epítome da atividade frívola, despropositada. Na esfera política, contudo, faz toda diferença se a pedra de mármore está próxima ao cume da montanha ou ao seu pé. Isto é, faz toda diferença se, por árduo esforço, nos encaminhamos para um estado de paz e liberdade republicana - ainda que jamais completamente consolidado - ou se, ao contrário, nos avizinhamos da guerra e do arbítrio despótico. Aos atores políticos é, pois, crucial perseverar em seu trabalho de Sísifo.

\section{REFERÊNCIAS:}

ARISTOTLE. Politics. Trad. Benjamin Jowett. Oxford: Clarenton Press, 1920.

BACHOFEN, Blaise. "Les raisons de la guerre, la raison dans la guerre. Une lecture des Principes du droit de la guerre". In: ROUSSEAU, Jean-Jacques. Principes du droit de la guerre; Ecrits sur la paix perpétuelle. Paris: Vrin, 2008.

BÉLISSA, Marc. Fraternité universelle et intérêt national (1713-1795). Les cosmopolitiques du droit des gens. Paris: Kimé, 1998.

BOUCHER D'ARGIS. “Sociedade (Moral)”. In: DIDEROT, Denis \& d'ALEMBERT, Jean le Rond (Eds.). Enciclopédia, ou Dicionário razoado das ciências, das artes e dos ofícios (vol. 4 - Política). Trad. Maria das Graças de Souza. São Paulo: Editora UNESP.

BERNARDI, Bruno. La fabrique des concepts: Recherche sur l'invention conceptuelle chez Rousseau. Paris: Honoré Champion, 2006.

DERATHÉ, Robert. Rousseau e a ciência política de seu tempo. Trad. Natália Maruyama. São Paulo: Discurso Editorial/Barcarolla, 2009.

DAMILAVILLE, Étienne. "Paix (Droit naturel, droit moral, droit politique)". In: DIDEROT, Denis \& d'ALEMBERT, Jean le Rond (Eds.). Encyclopédie, ou dictionnaire raisonné des sciences, des arts et des métiers. University of Chicago: ARTFL Encyclopédie Projet (Winter 2008 Edition), Robert Morrissey (Org.). Disponível on-line em: http://encyclopedie.uchicago.edu/

\begin{tabular}{|l|l|l|l|l|}
\hline Q Povista Dialectus & Ano 8 & n. 15 & Agosto - Dezembro 2019 & p. $143-155$ \\
\hline
\end{tabular}


DERRIDA, Jacques. Gramatologia. Trad. Miriam Chnaiderman e Renato Janine Ribeiro. São Paulo: Perspectiva, 2006.

DIDEROT, Denis. "Direito natural (moral)". In: \& d'ALEMBERT, Jean le Rond (Eds.). Enciclopédia, ou Dicionário razoado das ciências, das artes e dos ofícios (vol. 4 Política). Trad. Maria das Graças de Souza. São Paulo: Editora UNESP.

FABRE, Jean. "Deux frères ennemis: Diderot et Jean-Jacques". In: Diderot Studies, vol. III, n. 1. Paris: Librairie Droz, 1961.

FRINGS, Manfred. "Zur Idee des Friedens bei Kant und Max Scheler". In: Kant-Studien, vol. 66, n. $1,1975$.

GOYARD-FABRE, Simone. La construction de la paix, ou le travail de Sisyphe. Paris: Vrin, 1994.

. "La guerre et de droit international dans la philosophie de Rousseau". In: Études J.-J. Rousseau, n. 7. Montmorency: Musée Jean-Jacques Rousseau, 1995.

HOBBES. Thomas. Leviathan or the matter, forme, \& power of a common-wealth ecclesiasticall and civill. Londres: Andrew Crooke, 1651 (Edição eletrônica preparada por Rod Ray para o McMaster University Archive of the History of Economic Thought).

JACOURT, Louis de. "Lei natural (Direito natural)". In: DIDEROT, Denis \& d'ALEMBERT, Jean le Rond (Eds.). Enciclopédia, ou Dicionário razoado das ciências, das artes e dos ofícios (vol. 4 - Política). Trad. Maria das Graças de Souza. São Paulo: Editora UNESP.

LASSUDRIE-DUCHÈNE, Georges. Jean-Jacques Rousseau et le droit des gens. Paris: Henri Jouve, 1906.

LEPAN, Géralidine. Jean-Jacques Rousseau et le patriotisme. Paris: Honoré Champion, 2007.

PUFENDORF, Samuel. Le droit de la nature et des gens ou système général de la morale, de la jurisprudence et de la politique. Traduzido do latim por Jean Barbeyrac. Amsterdam: Pierre de Coup, 1734 (Edição reimpressa pela University of Toronto).

RADICA, Gabrielle. L'Histoire de la raison. Anthropologie, morale et politique chez Rousseau. Paris: Honoré Champion, 2008.

RAMEL, Frédéric \& JOUBERT, Jean-Paul. Rousseau et les relations internationales. Paris: L'Harmattan, 2000.

ROOSEVELT, Grace. Reading Rousseau in the nuclear age. Philadelphia: Temple University Press, 1990.

\begin{tabular}{|l|l|l|l|l|}
\hline Q Povista Dialectus & Ano 8 & n. 15 & Agosto - Dezembro 2019 & p. $143-155$ \\
\hline
\end{tabular}


ROUSSEAU, Jean-Jacques. "Idée de la méthode dans la composition d'un livre (Mélanges de littérature et morale)". In: Oeuvres Complètes, vol. II. Paris: Gallimard (Bibliothèque de la Pléiade), 1964.

. "Discours sur l'origine et les fondemens de l'inégalité parmi les hommes". In:

Oeuvres Complètes, v. III. Paris: Gallimard (Bibliothèque de la Pléiade), 1964a.

. "Du contract social ou Essai sur la forme de la République (Première version)".

In: Oeuvres Complètes, vol. III. Paris: Gallimard (Bibliothèque de la Pléiade), 1964b.

ROUSSEAU, Jean-Jacques. "Du contract social ou principes du droit politique". In: Oeuvres Complètes, vol. III. Paris: Gallimard (Bibliothèque de la Pléiade), 1964c.

. “Emile ou de l'éducation". In: Oeuvres Complètes, vol. IV. Paris: Gallimard (Bibliothèque de la Pléiade), 1969.

. Principes du droit de la guerre. Paris: Vrin, 2008.

SILVESTRINI, Gabriella. Diritto naturale e volontà generale. Il contrattualismo repubblicano di Jean-Jacques Rousseau. Torino: Claudiana, 2010.

SPECTOR, Céline. "De Diderot à Rousseau: la double crise du droit naturel moderne". In: BACHOFEN, Blaise, BERNARDI, Bruno \& OLIVO, Gilles (éds.) Rousseau, Du contract social, ou Essai sur la forme de la République (Manuscrit de Genève). Paris: Vrin, 2012.

VAUGHAN, Charles Edwin. "Introduction". In: The political writings of Jean-Jacques Rousseau, vol. I. Cambridge: Cambridge University Press (Edição digitalizada pela Open Library of Liberty), 1915.

\begin{tabular}{|l|l|l|l|l|}
\hline Qevista Qialectus & Ano 8 & n. 15 & Agosto - Dezembro 2019 & p. 143-155 \\
\hline
\end{tabular}

